\title{
Acute Ischemic Syndromes
}

\author{
Valter Correia de Lima
}

\author{
São Paulo, SP - Brazil
}

Coronary artery disease has a heterogeneous range of clinical presentations that varies from asymptomatic patients with multivessel disease to patients with one-vessel disease with acute myocardial infarction (AMI) and even sudden death. Other patients have stable angina that has evolved over many years, even decades, without progressing to unstable angina or myocardial infarction (MI). Even more serious, one third of the cases of coronary disease has sudden death as its first and only manifestation.

Despite being the main cause of death in developed countries, more people live with coronary atherosclerosis than die of it ${ }^{1,2}$. Therefore, the most relevant question is not why atherosclerosis develops, but why a quiescent atherosclerotic plaque suddenly ruptures and, on top of it, occlusive or subocclusive coronary thrombosis develops.

To understand this remarkable clinical heterogeneity is not easy, and only the recent advances in vascular biology have allowed the understanding of important aspects of this complex disease. This text focuses only on one form of this disease presentation, which is the acute ischemic syndrome (AIS).

\section{Pathogenesis}

The atherosclerotic plaque consists of two parts: the core (atheroma), which is rich in extracellular lipids, has a soft consistency, and occupies one third of the total volume of the plaque, and the peripheral component (sclerosis), which is formed by fibrous tissue, has a hard consistency, and occupies two thirds of the total volume of the plaque. The relative proportion of each component varies greatly, and there is no relation between plaque size and its constitution ${ }^{3,4}$.

The possibility of developing AIS does not depend solely on the number, distribution, and degree of stenosis caused by the atherosclerotic plaque. More than that, a complex balance between factors extrinsic to the plaque and their attributes not revealed by coronary angiography are currently considered.

Currently, the concept that AIS is usually precipitated by occlusive or subocclusive thrombosis on top of a com-

Hospital São Paulo - Escola Paulista de Medicina

Mailing address: Valter C. Lima - Rua Napoleão de Barros, 751 - Térreo CEP: 04024-002 - e-mail: vlima@uol.com.br plicated atherosclerotic plaque is widely accepted. According to this concept, plaque's disruption and the consequent exposure of its components to blood precipitates thrombosis ${ }^{3,5}$.

The factors determining rupture and subsequent thrombosis can be both extrinsic and intrinsic to the plaque.

\section{Extrinsic factors}

The extrinsic factors comprise the alterations of the formed elements and chemical components of the blood in addition to hemodynamic alterations. Several triggers of acute ischemic events have been identified ${ }^{2,6}$. Half of the acute ischemic events do not occur at random, being triggered by external factors. AMI occurs most frequently in the morning ${ }^{7-9}$, on Mondays ${ }^{10,11}$, during the winter ${ }^{12,13}$, and during emotional ${ }^{14,15}$ and physical ${ }^{16,17}$ stress. Physiologically, all these conditions have in common the increase of sympathetic tonus.

Muller et $\mathrm{al}^{2}$ clearly documented the daily variation in the incidence of MI, which tends to occur more often in the first hours of the morning than in any other period of the day. This observation confirmed that the typical adrenergic stimulus of waking up promotes platelet alterations and triggers coronary thrombosis. This evidence was confirmed by the observation that acetylsalicylic acid attenuated the morning peak of the occurrence of MI.

Later, Leor et al ${ }^{18}$ observed an increase in the incidence of infarction in Los Angeles in the hours and days following the Northridge earthquake. Curiously, these authors also noted a reduction in infarction incidence in the weeks and months that followed the earthquake. This observation suggests that the adrenergic stimulus associated with the natural disaster complicated a number of the atherosclerotic plaques vulnerable to disruption.

AIS can also be precipitated by hemodynamic changes that can cause modifications of the physical forces that operate on the atherosclerotic plaque. Bioengineering studies have documented a marked difference in physical stress in distinct regions of the plaque, contributing to its disruption and subsequent thrombosis. These studies revealed that the thicker the fibrous cap that covers the lipid core, the smaller the circumferential stress of the wall. In addition, the greater the volume of the lipid core, the higher the circumferential stress, especially at the transition bet- 
ween the plaque and the normal vascular wall. More curious, and less expected, is the observation that the degree of stenosis has a small influence on the physical stress of the plaque ${ }^{19-25}$. It was recently demonstrated that the maximum circumferential stress of the plaques responsible for fatal MI is three times higher than that of uncomplicated plaques. Furthermore, the disruption site coincided with the region of higher circumferential stress.

In addition to the prothrombotic influence of the adrenergic stimulus described above, there are also concomitant hemodynamic changes that probably increase the risk of plaque disruption. According to Laplace's law, the circumferential stress of the wall varies directly with the intraluminal pressure. Thus, the increase of blood pressure increases the circumferential stress in the plaque. The increase of inotropism and chronotropism that accompany the elevation of the adrenergic tonus also increases the compressive forces upon the plaque, favoring its disruption. Although intuitive, there is still lack of evidence of the importance of the hemodynamic changes in the increase of the risk of plaque disruption.

Another extrinsic factor to the plaque that influences its thrombotic potential is the alteration of the formed elements of the blood. It is currently known that the plasmatic concentration of fibrinogen increases the risk of coronary events independent of other factors ${ }^{26}$. There is a correlation between the variation in the levels of the plasminogen activator inhibitor 1 (PAI-1) and acute ischemic events, particularly MI in young individuals ${ }^{27,28}$. Another plasmatic factor is the increase of $\mathrm{Lp}(\mathrm{a})$ that competes with plasminogen and, therefore, inhibits plasmin activation. Because this is a fibrinolytic enzyme, the final fibrinolytic capacity is depressed.

This set of extrinsic factors to the plaque influences the precipitation of AIS because they disrupt the natural balance between thrombosis and fibrinolysis.

Other plasmatic factors that can affect plaque stability are the plasmatic levels of cytokines and endotoxins. These mediators of inflammation and systemic response to virus and bacteria can precipitate AIS when a severe systemic disease occurs. Interleukin-6, in particular, actuates in the liver, promoting acute phase protein synthesis. Another is fibrinogen, a plasma component surely related to ischemic events.

Although important, the extrinsic factors do not have an influence in the precipitation of AIS if there is no vulnerable plaque as a substrate.

\section{Intrinsic factors}

Contemporary pathological studies have established that the loss of integrity of the atherosclerotic plaque and subsequent thrombosis is the mechanism of the majority of AISs. There are two forms of loss of physical integrity of the plaque: erosion and disruption.

Erosion consists of a superficial loss of integrity with exposure of the subendothelial basement membrane. The exposed collagen activates the platelets and the von Wille- brand factor promotes their aggregation. Atherosclerotic plaque erosion is responsible for approximately one third of fatal coronary thromboses in autopsy studies.

Another form of loss of physical integrity is the disruption of the fibrous cap and subsequent wide exposure of its highly thrombogenic lipid core. Tissue factor, a potent procoagulant, significantly contributes to lipid core thrombogenic potential ${ }^{29,30}$. Tissue factor activates factor VII beginning the cascade of events that leads to the activation of factor X, thrombin, and finally to thrombus formation. This type of wider disruption is responsible for two thirds of the fatal coronary thromboses.

The disrupting region of the plaque usually exhibits inflammatory characteristics, especially the wider form of disruption through the fibrous cap ${ }^{31}$. Inflammation at the most vulnerable region of the plaque is characterized by elevated concentrations of macrophages and T lymphocytes, being independent from the plaque's morphology.

Microscopically, the complicated plaques responsible for fatal ischemic events have the following characteristics ${ }^{20,32}$ : 1) thin fibrous cap ${ }^{19,33,34}$;2) large lipid core ${ }^{33,34} ; 3$ ) abundance of macrophages ${ }^{24,31,35}$; 4) paucity of smooth muscle cell ${ }^{36-38}$.

The main factor responsible for the integrity of the fibrous cap is the interstitial collagen, particularly types I and III, which are predominantly synthesized by the smooth muscle cells. Therefore, any factor that reduces the amount of collagen in the fibrous cap can endanger its integrity.

The reduction of collagen in the fibrous cap can occur due to three mechanisms: 1) synthesis reduction;2) degradation increase; and 3 ) reduction in the amount of smooth muscle cells. Synthesis reduction can be mediated by interferon gamma that is produced by activated Tlymphocytes due to chronic inflammation ${ }^{39}$. Degradation increase depends on a set of proteolytic enzymes named matrix metalloproteinases (MMP). These enzymes, usually present in minimal amounts, have their synthesis increased by macrophages, particularly in the form of foam cells ${ }^{40-42}$. Although migration and proliferation of smooth muscle cells are an important component of the atherosclerotic plaque formation and growth ${ }^{43,44}$, these cells are characteristically scarce in the plaques responsible for fatal ischemic events. This must weaken the plaque because these cells are the main source of collagen. The probable mechanism for the reduction of the number of smooth muscle cells is interferon gamma cytokine synthesized by the activated $\mathrm{T}$ lymphocytes. Interferon gamma inhibits the proliferation of these cells and also activates their programmed death or apoptosis ${ }^{45-47}$. Three cytokines (interferon gamma, IL1 beta, and TNF-alpha) were recently observed to activate the apoptosis via the smooth muscle cell ${ }^{48}$.

Theoretically, a less common form of plaque rupture is called centrifuge, because it occurs inside the plaque towards the arterial lumen. This type of rupture requires that the intraplaque pressure surpass the intraluminal pressure. This can be precipitated by hemorrhage originating in the intraplaque vasa vasorum ${ }^{49,50}$. This hypothesis, however, still awaits confirmation. 
Another factor often considered as a cause of acute ischemic events is coronary spasm ${ }^{51,52}$. Even though the coexistence of spasm and plaque rupture is a common finding, the observations suggest that the first is more a consequence than a cause of the second ${ }^{53,54}$. In reality, it has been shown that drug-induced spasm rarely causes $\mathrm{MI}^{55}$.

\section{Clinical repercussions of plaque rupture}

Plaque rupture, most of the time, is a common and asymptomatic phenomenon. Its clinical repercussion depends on the degree of coronary flow limitation caused by subsequent thrombosis, which is very variable ${ }^{3}$. Autopsy studies reveal that $9 \%$ of "normal" individuals who die of noncardiac causes have coronary plaque complicated with rupture. This finding increases to $22 \%$ in individuals with diabetes or hypertension ${ }^{56}$. On the other hand, in two other studies of individuals who died from coronary artery disease, many coronary plaques complicated by rupture were found ${ }^{35,57}$. The complicated plaques that caused the death showed intense thrombosis with coronary flow limitation, and the majority of the other complicated plaques had discreet or no thrombosis.

Therefore, after plaque rupture, the degree of thrombosis determines the clinical repercussion. The three main factors that determine the intensity of the thrombotic response to rupture are: 1) rupture extension and composition of plaque contents ${ }^{58-60} ; 2$ ) the degree of stenosis and irregularity of the plaque surface ${ }^{61,62 ; 3)}$ balance between thrombotic and thrombolytic factors at the moment of rupture ${ }^{63-67}$.

In the majority of patients with unstable angina, plaque erosion or rupture resolves with the vascular reparation process that results in an increase of the degree of obstruction.

The type of AIS that a given patient develops after rupture and subsequent thrombosis is determined by four factors: 1) vessel occlusion velocity; 2) degree of obstruction: total or partial;3) magnitude of collateral circulation to the distal bed of the occluded artery; and 4) occlusion stability: long-standing or transitory.

\section{Coronary thrombosis in unstable angina and AMI: similarities and differences}

Today it is well established that AIS consists of a continuum spectrum ranging from unstable angina to AMI. These syndromes have several aspects in common, such as variable degree of plaque rupture, variable degree of subsequent thrombosis, ischemia usually determined by primary reduction of oxygen supply due to long-lasting or transitory coronary occlusion or subocclusion. There are, however, important differences in pathophysiology, which determine fundamental differences in clinical features, response to treatment, and prognosis (between unstable angina and AMI).

Clinically, unstable angina has several forms of presentation resulting in different definitions and classifications. On the other hand, AMI has a form of presentation that enables a more specific definition.
Several classifications for unstable angina have been developed, according to clinical, pathophysiological, and prognostic criteria ${ }^{68-70}$. The classification that has been most used by clinicians and epidemiologists is the one by Braunwald $^{71}$. This classification encompasses three criteria: 1$)$ severity of pain: recent effort angina ( $<2$ months) or progressive angina (aggravation of previous stable angina) (class I), subacute angina at rest, with the last painful episode more than 48 hours before (class II), acute angina at rest, with the last painful episode within the last 48 hours (class III);2) clinical circumstance of angina occurrence: secondary (A), primary (B), and postinfarction (C); 3) presence of any form of treatment at the moment of angina presentation: none (1), oral treatment (2), maximum pharmacological treatment (3). In each of these criteria, there is a progressive scale of prognosis aggravation. Therefore, the most benign unstable angina is class IA 1 ; the one with the worst prognosis is class IIIC $3^{72}$. According to data obtained in the Global Unstable Angina Registry and Treatment Evaluation (GUARANTEE Study) ${ }^{73}$, which involved almost three thousand patients, two thirds of the cases are class II or III (subacute or acute angina at rest) and one third is class I (recent effort angina or progressive angina).

Myocardial ischemia in AISs, such as ischemia in any tissue, can result from increase in oxygen demand or reduction in oxygen supply. The increase of oxygen demand causes approximately one third of the cases of unstable angina (Braunwald class I) and rarely AMI. On the other hand, the reduction of the oxygen supply accounts for two thirds of unstable angina cases and almost all of the AMI cases.

Class II and III unstable angina and AMI are caused by atherosclerotic plaque rupture and subsequent subocclusive and occlusive thrombosis, respectively. As above described, plaque complication occurs in variable degrees from small erosion and localized fissure to extensive and deep rupture. There is a clear relation between the degree of the plaque's anatomical complication and the clinical expression of this complication. A great number of the small erosions and ulcerations of the plaque are clinically silent. Falk ${ }^{74}$ and several other researchers ${ }^{75}$ have histologically and angiographically demonstrated that coronary stenosis causing unstable angina results from repetitive episodes of plaque ulceration and healing, which cause a slow increase of the plaque's volume. Vascular repair subsequent to ulceration and thrombosis can increase the fibrous content through thrombus organization and incorporation to the plaque. This not only limits the extension of the subsequent complication, but also makes the plaque less vulnerable to future ruptures, which can be interpreted as a natural mechanism of arterial passivation.

In unstable angina, coronary thrombosis is usually subocclusive or transitorily occlusive. This type of thrombus is typically fragile and can cause periods of occlusion of 10 to 20 minutes ${ }^{76}$, frequently with a concomitant and transitory coronary spasm component. Spasm can be caused by release of vasoactive substances by platelets and endothelial dysfunction ${ }^{77}$. 
In non-Q MI, the degree of plaque injury is more significant than in unstable angina, resulting in more persistent occlusive thrombosis, lasting up to one hour ${ }^{76}$. Approximately one forth of the patients with non-Q infarction have a persistently occluded coronary artery responsible for the infarction, but also have the distal bed partially protected by collateral circulation.

In AMI, plaque rupture is often more extensive and deeper, with intense collagen, cholesterol crystals, and tissue factor exposure, and consequent long-lasting occlusive coronary thrombosis. It is important to emphasize that no relation exists between the degree of stenosis caused by a plaque and the extension and depth of an eventual rupture. It was recently observed that $40 \%$ of the fatal occlusive coronary thrombi occurred in plaques complicated only by erosion ${ }^{78}$. This observation led to the consideration that circulating or systemic (monocytes, infection, hypercholesterolemia, etc) hemostatic factors can play a significant role in these cases. In addition, half of the AMI cases are caused by atherosclerotic plaques that reduce the luminal diameter to $50 \%$ or less, being therefore considered of little prognostic value in infarction-preceding angiographies ${ }^{78}$.

Some cases of sudden death probably involve rapidly progressive coronary injury, where plaque rupture and the resulting occlusive thrombosis lead to myocardial ischemia and fatal ventricular arrhythmia in the absence of collateral circulation ${ }^{79}$.

Thrombosis following plaque rupture is a process that evolves in stages and begins with exposure of subendothelial components, such as collagen, von Willebrand factor, fibronectin, and vitronectin. These extracellular matrix components are recognized by the surface receptors of the platelets, which then adhere to the plaque and become activated. The activated platelets release a set of substances from their alpha granules, causing vasoconstriction, chemotaxis, mitogenesis, and more platelet activation. The substances involved in this process are thromboxane A2, serotonin, fibrinogen, plasminogen-activator inhibitor (PAII), and growth factors. Platelet activation leads to exposure of a particular surface receptor, glycoprotein IIb/IIIa. This integrin is the via final common pathway of all platelet aggregation agonists, and is also known as fibrinogen receptor ${ }^{80}$. Aggregation consists of ligation and connection between multiple platelets, occurring through fibrinogen bridges and accelerating thrombin production. In a reciprocal manner, the generated thrombin is a potent platelet activator that stabilizes the thrombus, converting fibrinogen into fibrin.

Sherman et al ${ }^{81}$ performed angioscopy on 10 patients with unstable angina. Angioscopy revealed exuberant structural abnormalities in the intima of all patients and thrombus in seven. Patients with progressive angina had plaques with complex morphology, and those with angina at rest had nonocclusive thrombus at the moment of the examination.

As coronary thrombosis is responsible for the great majority of AISs, some researchers tried to identify plasmatic markers of thrombosis and platelet aggregation. Fibrinopeptide A (FPA) is a polypeptide resulting from the trans- formation of fibrinogen into fibrin mediated by thrombin. Patients with unstable angina have serum levels of FPA much higher than patients with stable angina or with chest pain of noncardiac origin ${ }^{82}$. Other authors reproduced these findings ${ }^{83,84}$. Zalewski et al ${ }^{85}$ observed elevated levels of PAI-I, a marker of platelet aggregation, in patients with unstable angina. Fitzgerald et al ${ }^{86}$ verified that $84 \%$ of the episodes of angina at rest were associated with transitory elevation of thromboxane, suggesting a temporal relation between platelet activation and a clinical event. Some controversial data in relation to the presence of plasmatic markers of active thrombosis can be attributed to the heterogeneity of the patients with unstable angina studied, to the small amount of thrombus present in some lesions, and to the transitory presence of the hemostatic factors in circulation ${ }^{87}$.

\section{Epidemiology}

AISs are the main cause of adult hospitalization in the United States. In recent years, the incidence of unstable angina has rapidly increased. With better population information, longer survival of patients with AMI, population aging, and better diagnostic efficiency of chest pain of ischemic origin, this incidence should continue to increase. In many coronary care units, unstable angina surpassed AMI as the main cause of hospitalization in the last decade ${ }^{88}$. In the US, it is estimated that there are 700000 hospitalizations annually due to unstable angina and another 700000 cases occur in which the diagnosis either is not made or the patients are treated on an outpatient basis. It is also estimated that 1.5 million cases of AMI occur and that $20 \%$ of patients die prior to medical care ${ }^{89}$. Only $30 \%$ to $50 \%$ of the patients hospitalized with a suspicion of AMI have the diagnosis confirmed $^{78}$. Therefore, AIS occurs in epidemic proportions.

\section{Clinical, electrocardiographic and enzymatic features}

Chest pain of unstable angina differs from that of stable angina mainly because it is more unpredictable, intense and longer lasting. On the other hand, patients with AMI present with a typically more intense and longer-lasting chest pain, accompanied by other clinical signals, such as dyspnea, nausea, vomiting, and intense sweating. However, the presentation can be similar to that of an episode of unstable angina. In this case, diagnostic differentiation in the emergency room is provided by electrocardiogram (ECG), which is characterized by ST segment elevation.

ST segment elevation in the presence of precordial pain is generally interpreted as transmural infarction caused by occlusive thrombosis of the coronary artery responsible for the infarction. On the other hand, ST segment depression indicates subendocardial ischemia of unstable angina or of non-Q infarction caused by coronary subocclusive or transitory and recurrent occlusive thrombosis.

Therefore, no matter what the clinical presentation of the AIS at the emergency room is, the main information for 
the immediate diagnostic definition in order to guide the treatment of recanalization is the presence or absence of ST segment elevation. Less common is the clinical presentation of AMI and ECG with left bundle branch block, a situation that has the same interpretation and treatment as that of patients with ST segment elevation ${ }^{78}$.

Among the patients in the emergency room with chest pain that causes suspicion of coronary artery disease, there are two aspects of evaluation that are complementary and equally important: evaluation of the risk of coronary artery disease and evaluation of the risk of unfavorable clinical evolution ${ }^{90}$. At the end of this evaluation, the diagnosis can be one of the following: chest pain of noncardiac origin, stable angina, unstable angina, or AMI.

A diagnostic and prognostic resource of growing use in the evaluation of patients with unstable angina is the dosage of the enzyme troponin T and I. These enzymes are usually absent or present in very small amounts in the plasma. In the presence of chest pain that causes a suspicion of unstable angina, the abnormal presence of these enzymes is an important marker for the occurrence of future clinical events such as infarction and death ${ }^{91-93}$.

\section{Coronary angiography}

Coronary angiography has contributed in a significant way to the understanding of AISs through the historical studies of DeWood ${ }^{94}$ and Ambrose ${ }^{95}$. Serial angiographies of patients with unstable angina have shown one, two or three vessel disease in $15 \%, 35 \%$, and $50 \%$, respectively ${ }^{96-98}$. Coronary artery disease extension in patients evaluated in these studies is greater than that observed in patients with stable angina and MI. The TIMI IIIA study ${ }^{99}$, which evaluated the effect of thrombolysis in unstable angina showed one, two or three vessel disease in $35 \%, 39 \%$, and $26 \%$, respectively, which is similar to the findings in patients with stable angina. When all the patients with unstable angina who underwent coronary angiography are considered, a significant stenosis of the left main coronary artery is observed in $5 \%$ to $10 \%$ of the patients, but $10 \%$ to $15 \%$ exhibit normal coronary arteries or nonsignificant stenoses.

The incidence of thrombus revealed by coronary angiography in unstable angina varies from $<10 \%$ in patients with pain in the 30 days preceding the catheterization ${ }^{100}$ until $>50 \%$, in those with pain at rest in the last 24 hours ${ }^{101-103}$.

An important aspect that favors the indication of early coronary angiography in patients with unstable angina is that almost half of these patients have coronary multivessel disease or stenosis of the left main coronary artery, benefiting, therefore, from early surgical revascularization.

Coronary angiography in the first hours of the evolution of infarction was first described by DeWood et al ${ }^{94}$, who verified that occlusive coronary thrombosis was present in $85 \%$ of the cases with transmural infarction. With time, spontaneous recanalization occurs in up to half of the patients. These findings had a great impact in the modern treatment of AMI, concentrating all efforts in the early restoration of the coronary flow with thrombolysis or coronary angioplasty.

\section{Treatment}

The pathophysiological substrates of unstable angina and AMI have similarities that also lead to a strategy of pharmacological treatment with similarities. The pathophysiological similarities of plaque rupture, subsequent thrombosis, and ischemia of supply due to coronary occlusion or subocclusion demand control of the thrombotic process and reestablishment of the balance between oxygen supply and consumption. These objectives are met with antithrombotic and antiischemic drugs. The basic pathophysiological difference between unstable angina and AMI, however, is that in unstable angina, the coronary flow is only transitorily interrupted, but in AMI there is a lasting coronary occlusion due to the thrombus. Therefore, in AMI the primary and immediate treatment goal is to reestablish the flow with reperfusion therapy. On the other hand, in unstable angina, the treatment aims to avoid the progression of the subocclusive or transitorily occlusive coronary thrombosis to stable and long-lasting coronary thrombosis. This strategy is mainly based on the data analysis of the Fibrinolytic Therapy Trialists' Collaborative Group ${ }^{104}$. This group of investigators combined the results of nine large scale studies of thrombolysis, including 58.6 thousand patients, of whom 32,346 with AIS ST segment elevation and 4,237 with depression of the ST segment. The group with ST segment elevation treated with thrombolysis had a $19 \%$ higher survival rate than that treated with placebo. The group with ST segment depression had a $10 \%$ smaller survival rate.

As this is a fundamental and urgent difference, at the emergency room AIS should be seen as composed of two distinct groups based on the ECG: AIS with and without ST segment elevation. The first group should be consistently considered for chemical or mechanical recanalization, and the second group should be considered only for antiplatelet, antithrombin, and antiischemic therapy.

\section{Unstable angina}

Immediate clinical treatment must be initiated in any patient suspected of unstable angina. The treatment objectives are the control of myocardial ischemia symptoms, and prevention of evolution to MI and death.

The antiischemic treatment consists of reduction of physical activity, BP control, and administration of antianginal drugs.

Patients with progressing or recent angina (Braunwald class I) can be initially treated on an outpatient care basis. The majority of these cases have a good response and the patients become asymptomatic or olygosymptomatic with acetylsalicylic acid, beta-blocker and nitrates by oral or topical via. If clinical risk assessment is favorable, these 
patients remain this way; if it is unfavorable, they should be referred for catheterization, followed or not by percutaneous or surgical revascularization, depending on the anatomy and extension of the coronary artery disease.

Patients with angina at rest and last painful episode more than 48 hours before (Braunwald class II) should also initiate outpatient care treatment, except if considered of intermediate or high risk for MI or death. In this case, they must be hospitalized, begin oral treatment with acetylsalicylic acid, heparin, beta-blocker and nitrate, and be carefully observed for 24 to 48 hours for recurrence of symptomatic myocardial ischemia and dynamic electrocardiographic abnormalities.

Patients with angina at rest and painful episodes within the last 48 hours (Braunwald class III) should be admitted to the coronary unit, begin treatment with acetylsalicylic acid, heparin and nitroglycerin intravenously, and beta-blocker, intravenously or orally. Patients who evolve with recurrent angina, despite the treatment, should undergo urgent catheterization aiming to define the coronary anatomy and, if indicated, proceed to percutaneous or surgical revascularization.

These recommendations were published in $1994{ }^{105}$ and have usually been questioned or even ignored because of the recent and dramatic pharmacological advances (platelet glycoprotein IIbIIIa inhibitors, low-molecularweight heparin) and improvement of the results of coronary angioplasty due to the widespread use of stents. These advances have led to a more aggressive initial strategy with early catheterization followed by angioplasty and early hospital discharge, frequently before 48 hours. Although attractive and apparently more economical because this strategy shortens hospitalization, one should wait for evidence coming from large-scale randomized multicenter clinical trials before universally recommending it.

Nitrate administration continues to be routine both for treatment and for prevention of anginal crises. Nitrates can be administrated topically, by oral or sublingual via, or intravenously. Through the relaxation of the endotheliumindependent smooth muscle cell, nitrates reduce the venous return and the BP. These two effects decrease the wall stress and, therefore, myocardial oxygen demand. Clinically less important is the coronary vasodilating effect, particularly upon spasm-aggravated stenosis. Intravenous nitroglycerin is indicated for high-risk patients or those with recurrent angina at rest. In addition to angina control, nitrates help to control BP and ventricular dysfunction. As tolerance to hemodynamic effects develops quickly, an interruption is recommended after 24 to 48 hours of use ${ }^{106}$. In regard to hemostasis, nitroglycerin was observed to have a transitory plateletantiaggregating effect on the one hand, but it can also induce resistance to the anticoagulant effect of heparin.

Beta-blockers are widely used in unstable angina because they increase the threshold for angina occurrence, prevent recurrent ischemia and death following $\mathrm{MI}^{107}$. They are specifically effective when there is evidence of sympathetic tonus increase characterized by tachycardia andhypertension.
Calcium antagonists are effective in the prevention of recurrent ischemia, particularly those having a negative chronotropic effect. Nifedipine, however, should only be used in association with a beta-blocker, because, isolated, it increases the incidence of clinical events, as demonstrated in the HINT (Holland Interuniversity Nifedipine/Metoprolol Trial) ${ }^{108}$. Antithrombotic treatment in unstable angina consists of administration of antiplatelet and antithrombotic agents, aiming to control plaque thrombosis. As coronary flow is usually preserved, there is no indication of recanalization. In fact, the thrombolytic agent is contraindicated because it increases platelet activation and aggregation leading, therefore, to more thrombosis and worse clinical outcome ${ }^{104,109}$.

The standard antiplatelet agent in AIS is acetylsalicylic acid. Its efficacy has been consistently proved. Acetylsalicylic acid reduces the risk of fatal and nonfatal MI in $71 \%$ in the acute phase ${ }^{110,111}$, in $60 \%$ in three months ${ }^{111,112}$, and in $52 \%$ in two years ${ }^{113}$. The beneficial mechanism of acetylsalicylic acid is the irreversible inhibition of cyclooxygenase, blocking the formation of thromboxane A2 and platelet aggregation. In order to achieve the cyclooxygenase blockade more rapidly, an initial dose of 160 to $325 \mathrm{mg}$ is recommended. The maintenance dose can vary from 80 to $160 \mathrm{mg}$ daily. The dose of $80 \mathrm{mg}$ daily is as effective as higher doses and causes fewer collateral effects. Another antiplatelet agent used when acetylsalicylic acid is contraindicated is ticlopidine, which inhibits platelet aggregation mediated by ADP and inhibits platelet glycoprotein IIbIIIa activation. Ticlopidine at a dose of $250 \mathrm{mg}$ twice a day reduced in $46 \%$ the risk of fatal and nonfatal MI in six months, when compared to placebo ${ }^{114}$. The benefit, however, only became apparent 10 days after the beginning of treatment, which supports the already known late onset of activity of this drug.

The development of a new group of antiplatelet agents, the platelet glycoprotein IIbIIIa inhibitors, has changed the treatment scenario and perspective of AISs, focusing the strategy more on the control of the thrombus white (platelet) component ${ }^{115}$. The first compound of this group to be widely tested in randomized multicenter trials was abciximab, which is a monoclonal antibody against the platelet glycoprotein IIbIIIa, the final common pathway of platelet aggregation. Other molecules of parenteral use are eptifibatide or integrilin, a peptide, and tirofiban and lamifiban, nonpeptide compounds. Abciximab was tested with huge success, as an adjunct of coronary angioplasty, aiming to reduce its complications, such as acute occlusion, AMI and urgent reintervention ${ }^{116,117}$. A particular study, CAPTURE ${ }^{118}$, tested abciximab in a population with refractory unstable angina, whose vessels responsible for the clinical event were adequate to percutaneous revascularization. The drug was administered for 18 to 26 hours prior to angioplasty, followed by infusion during one hour after the procedure. There was reduction of the combined objectives (death, non-fatal infarction, or emergency revascularization) from $15.9 \%$ to $11.3 \%(\mathrm{p}=0.012)$ at the 30th day and no benefit at the sixth month. 
Tirofiban, used in association with acetylsalicylic acid and heparin, was recently tested in the treatment of unstable angina and non-Q MI. It proved efficient in reducing death and incidence of nonfatal MI in 48 hours from $2.6 \%$ to $0.9 \%$ (reduction of $66 \%$ ), and in 30 days from $11.9 \%$ to $8.7 \%$ (reduction of $30 \%$ ), when compared to the combined use of only acetylsalicylic acid and heparin ${ }^{119}$. Eptifibatide, used in association with acetylsalicylic acid and heparin, was also tested in unstable angina and also proved efficient in reducing nonfatal MI and death from $15.7 \%$ to $14.2 \%$ (reduction of $9 \%)^{120}$. In this study, refractory ischemia was not considered in the combined objective, which might explain the smaller reduction of events of $9 \%$, instead of $30 \%$ of PRISMPLUS ${ }^{119}$. In both studies, the benefit was more evident in the group of patients that later underwent coronary angioplasty, which comprised one third of the cases. In view of these favorable results, tirofiban and eptifibatide were recently approved for clinical use. However, in patients surviving an episode of unstable angina or MI, local activation of the hemostatic system lasts for months, causing recurrence of acute ischemic events. Two trials with platelet glycoprotein IIbIIIa inhibitors, RESTORE ${ }^{121}$ and CAPTURE ${ }^{118}$, and one with thrombin direct inhibitor, GUSTO IIb ${ }^{122}$, consistently showed early benefit. This benefit, however, was variable and declined considerably over time, coinciding with the interruption of the administration of the drug. Therefore, more than one dozen oral platelet glycoprotein IIbIIIa inhibitors that might be active for a long period are being exhaustively investigated.

Heparin is recommended for the treatment of unstable angina based on innumerous randomized studies of moderate size that are strengthened by metaanalysis ${ }^{123,124}$. Heparin is usually intravenously administered in bolus of 5 thousand units, followed by continuous infusion in the necessary dose to keep the activated partial thromboplastin time two times the basal value. Due to low bioavailability and necessity of monitoring the anticoagulation of unfractioned heparin, the efficiency of low-molecular-weight heparins has been tested. The FRISC Study ${ }^{125}$ showed therapeutical equivalence between dalteparin and unfractioned heparin. The ESSENCE Study ${ }^{126}$ showed the superiority of enoxiparin, which reduced the incidence of nonfatal MI, death and recurrent angina from $23.3 \%$ to $19.8 \%$ in 30 days, an absolute reduction of $3.5 \%$ and relative reduction of $15 \%$ $(\mathrm{p}=0.019)$. In these two studies, low-molecular-weight heparin was administered for a few days and new studies are assessing the possibility of extending the benefit, maintaining the administration for several weeks after hospital discharge. The advantages of low-molecular-weight heparins are its subcutaneous administration and predicting degree of anticoagulation, which eliminates the need for monitoring.

Another antithrombotic drug still under research is hirudin, a direct thrombin inhibitor. A preliminary study with high doses was prematurely interrupted due to the occurrence of hemorrhagic complications ${ }^{127}$. A low-dose study showed benefits in the first days, but these benefits signifi- cantly decreased in the following 30 days ${ }^{122}$. A great study testing a moderate dose of hirudin is being carried out based on the favorable results of a pilot study ${ }^{128}$.

Considering the placebo group of several recent mega trials on unstable angina, the prognosis of this syndrome with conservative treatment with acetylsalicylic acid, heparin, nitrate, beta-blockers and calcium antagonists is poor, evolving to death or mainly nonfatal MI in $11 \%$ of the cases. Aiming to improve this prognosis, two randomized studies compared the conservative clinical treatment with an invasive initial strategy of myocardial revascularization: the National Cooperative Study and the Veterans Administration Cooperative Study ${ }^{96,129}$. Both studies reported that survival is similar with the two strategies. In the first study, the one-year survival was $92 \%$ and $93 \%$ in the surgical and clinical groups, respectively. There was, however, considerable transfer from the clinical to the surgical group, in these two studies, and this index was $19 \%$ in one year and $34 \%$ in two years. In the Veterans Administration Cooperative Study, the advantage of surgical compared to clinical treatment in two groups of patients was particularly significant. The five-year survival of patients with multivessel disease was $89 \%$ for the group that underwent surgery and $75 \%$ for the group clinically treated ${ }^{96}$. Among patients with ventricular dysfunction and ejection fraction between $30 \%$ and $49 \%$, the survival for the surgical group was $86 \%$ compared to $73 \%$ for the clinical one.

With the development and wide spread utilization of coronary angioplasty, the clinical trials were reoriented to compare the clinical treatment and the invasive treatment with angioplasty or surgery, depending on coronary anatomy. On the other hand, the Veteran Affairs non-Q Wave Infarction Strategies in Hospital Study (VANQWISH) ${ }^{130}$ reported a better hospital and one year clinical outcome with the conservative strategy. The incidence of death and nonfatal MI during the hospital phase was $3 \%$ and $8 \%$, respectively, in one year, and $18.5 \%$ and $24 \%$ with clinical and early invasive (surgery or angioplasty) treatment, respectively. It is important to stress that the revascularization index in 18 months was $44 \%$ in the randomized group for the early aggressive strategy and $33 \%(p=N S)$ in the randomized group for the initial conservative strategy. Therefore, this data analysis suggests that clinical and invasive (angioplasty or surgery) treatments are more additive or complementary than competitive therapeutical options. When the revascularization option is required, the choice between angioplasty or surgery is guided by coronary disease extension, morphological aspects of the lesions, estimated risk and awaited benefit of each procedure, and, not rarely, by the patient's preference, when both options are equivalent and this option is offered to the patient by the assistant physician. In fact, the comparison between angioplasty and surgery in patients with multivessel disease has shown a similar survival, except for the patients with left main coronary arterial disease and diabetic patients with multivessel disease ${ }^{131,132}$. The majority of patients with unstable angina are well-controlled with clinical treatment, 
without recurrence of the myocardial ischemia and have a favorable prognosis. These patients may not need routine catheterization and can be properly stratified with noninvasive tests of ischemia. A negative exercise test after stabilization of eliminates the possibility of demand myocardial ischemia related to severe stenosis and is associated with a low incidence of clinical events in the late follow-up. Patients with positive exercise (or any other imaging ischemic test) test are indicative of severe stenosis and should be referred for invasive stratification with catheterization. Patients with angina after MI or those who do not stabilize with clinical treatment are considered high-risk for MI recurrence or death, and should also undergo catheterization aiming to identify a critical coronary stenosis that can benefit from percutaneous revascularization or surgery. Recurrence of ischemia in unstable angina in the presence of clinical treatment indicates lack of disease control, presence of critical coronary stenosis, or multivessel disease. Intraaortic balloon is often indicated to stabilize the more unstable patients, as a bridging procedure for the more definitive treatment of the disease ${ }^{133}$.

\section{Acute myocardial infarction}

Three contributions had a huge impact on the modern treatment of AMI: first, DeWood et al ${ }^{94}$ performed coronary angiography in patients with AMI and verified that $85 \%$ of the cases had evidence of occlusive coronary thrombosis in the first hours of onset; second, Rentrop et al ${ }^{134}$ demonstrated acute reperfusion with intracoronary infusion of streptokinase; third, Reimer et al ${ }^{135}$ demonstrated that, in dogs, coronary occlusion causes a wave of necrosis that progresses from the endocardium to the epicardium, in a few hours, and that flow restoration in the first three hours preserves part of the myocardium at risk. These anatomical and pathophysiological observations guide all established or under investigation treatment strategies.

\section{Thrombolysis}

More than 200000 patients were studied in randomized clinical trials in order to test the efficiency of the thrombolytic treatment. Around 65000 were randomized to compare thrombolysis with placebo or control treatment, and the rest was randomized to compare different thrombolytic drugs and regimens. Hospital mortality of AMI was reduced from around $15 \%$ to $8 \%$ with thrombolytic treatment ${ }^{136,137}$. Despite this brilliant clinical result, the hypothesis of the open artery in the AMI had often been questioned. Initial studies on early coronary patency revealed that t-PA (tissue plasminogen activator) was more efficient than streptokinase ${ }^{138,139}$. However, there was no difference in the mortality indices between these two thrombolytic agents in large-scale randomized studies, such as GISSI II ${ }^{140}$ and ISIS III ${ }^{141}$. Then, the hypothesis that t-PA dose and administration regimen may have been inadequate in these studies appeared, leading to the speculation that t-PA superiority may have been mas- ked. These considerations stimulated the design of GUSTO I (Global Utilization Strategies to Open Occluded Coronary Arteries) ${ }^{142}$. This clinical trial was enriched with an angiographic substudy investigating the relation between early coronary patency and clinical outcome ${ }^{143}$. In GUSTO I, 41,021 patients were randomized for four different thrombolytic strategies: streptokinase plus intravenous or subcutaneous heparin, accelerated t-PA plus intravenous heparin, and streptokinase plus t-PA plus intravenous heparin. The regimen presenting the highest reperfusion index at 90 minutes was t-PA plus intravenous heparin. This was the regimen with the smallest mortality rate (6.3 versus 7.3 for streptokinase plus intravenous heparin, $\mathrm{p}=0.001$ ). Mortality reduction was already evident after 24 hours. Normal coronary flow in angiography (TIMI III) at 90 minutes occurred in $54 \%$ with $t-P A$, versus $31 \%$ with streptokinase $(\mathrm{p}<0.001)$. However, there was no difference at 180 minutes $(43 \%$ versus $38 \%$, $\mathrm{p}=\mathrm{NS}$ ), suggesting that the difference between the two thrombolytic agents lies in the precocity of recanalization and not in the recanalization rate. These angiographic observations emphasized the importance of the precocity of coronary patency caused by thrombolysis. The difference in 30-day mortality can be accurately anticipated ( $\mathrm{r} 2=0.92)$, based on the difference of the TIMI III flow index, at 90 minutes ${ }^{144}$. The coronary artery patency related to the infarction was also associated with a higher late survival. Among the 12,864 patients of GUSTO I who underwent angiography, the mortality at one year was smaller when the artery was found patent than when it was closed: $3.3 \%$ versus $8.5 \%$ in the clinically treated patients, $2.5 \%$ versus $8.5 \%$ in those who underwent angioplasty, and $4.2 \%$ versus $9.6 \%$ in those who underwent myocardial revascularization ${ }^{145}$. Early and thorough reperfusion not only reduces 30-day and one-year mortality, but it also results in decreased cardiac morbidity ${ }^{146}$, with a smaller incidence of heart failure, atrial fibrillation, atrioventricular and intraventricular conducting disorders, and ventricular arrhythmia.

To confirm the open artery hypothesis, it was observed that reocclusion eliminates the benefit of the initially successful thrombolysis ${ }^{147}$. In addition, independent from the thrombolytic regimen used, the 30-day mortality of the patients without recanalization or with only partial recanalization was $8.9 \%$ and of the patients with thorough recanalization was $4.0 \%$.

GUSTO I is a landmark study in the modern treatment of AMI because it demonstrated that reperfusion obtained with thrombolysis preserves myocardium and lives, and that this benefit depends primarily on its capacity for early, thorough and maintained reperfusion.

The choice between streptokinase and t-PA, the two most commercially available thrombolytic agents, should involve consideration of the clinical benefits desired and the cost:effectiveness ratio. These considerations have led to the proposition of an individualized strategy determined by the initial risk stratification ${ }^{148}$. The high risk markers for death are: age $\geq 65$ years, female gender, previous ventricu- 
lar dysfunction, anterior wall infarction, complete left bundle branch block, marked ST segment elevation, diabetes, heart rate $\geq 100 \mathrm{bpm}$, and systolic $\mathrm{BP}(\mathrm{SBP})<100 \mathrm{mmHg}$ at the moment of hospital admission. In patients with pain for less than 4 hours, the reperfusion speed is crucial, recommending the accelerated t-PA, except in patients with low risk of death (young people with inferior infarction) and high risk of cerebral hemorrhage $(\mathrm{BP} \geq 170 / 110 \mathrm{mmHg})$. In these patients, t-PA and streptokinase are equivalent options, except for the higher cost of t-PA. For patients with pain between 4 and 12 hours, low risk of death, but high risk of cerebral hemorrhage (age $>65$ years with inferior infarction, and SBP > 100mmHg), streptokinase must be the thrombolytic agent of choice.

Ohman et al ${ }^{149}$ demonstrated that early reocclusion determines deterioration of the ventricular function and doubles the rate of mortality. The incidence of reocclusion varies from $4.9 \%$ to $25 \%$, depending on the thrombolytic agent and the adjunct therapy ${ }^{143,150}$. Reocclusion until one year after reperfusion can occur in $25-30 \%$ of the early recanalized arteries ${ }^{146,151}$. As late patency of the infarctionrelated artery is an independent prognostic factor, even silent late reocclusion can impair the long-term clinical outcome ${ }^{144,145}$. The observation that reduction in mortality often surpasses the impact obtained in the degree of ventricular dysfunction stimulated the hypothesis that even late reperfusion can cause clinical benefits through mechanisms different from those of myocardial preservation ${ }^{152-154}$. These mechanisms can be: flow provision for collateral circulation ${ }^{155,156}$, electrical stability ${ }^{157,158}$, reduction of wall stress and aneurysm formation, attenuation of ventricular remodeling and dilation ${ }^{159,160}$. At least two studies confirmed that coronary arterial patency is an important predictor of late survival independent from ventricular function ${ }^{161,162}$. In order to accelerate reperfusion, reduce the resistance to thrombolysis and prevent reocclusion, several new antithrombotic agents, such as direct antithrombinic agents, lowmolecular-weight heparins and antiplatelet agents, are currently being tested in addition to new thrombolytic agents.

New thrombolytic agents, specifically the plasminogen activators, have been developed and have the following properties: longer plasmatic half-life, which allows bolus administration, higher specificity for fibrin, and higher resistance to the natural inhibitors of the thrombolytic agents, such as PAI-I. The following agents are in different phases of commercial availability or clinical investigation and have been compared in large-scale randomized studies with accelerated t-PA, the thrombolytic regimen considered the gold standard, or with streptokinase: reteplase or r-PA(INJECT and GUSTOIII), lanoteplase orn-PA(InTIME2), TNK-tPA (ASSENT-2), saruplase (COMPASS), staphylokinase and an alpha1-plasminogen activator derived from the saliva of the snake Desmodus rotundus. GUSTO III demonstrated equivalence between t-PA and r-PA at the endpoints of death and disabling stroke. The final results of the studies InTIME-2 and ASSENT-2 are expected during the first semester of 1999 .
All the studies search for the ideal thrombolytic agent, which should present the following properties: quick recanalization (15-30 minutes), recanalization index close to $100 \%$, quick administration in a single bolus, low index of cerebral and systemic hemorrhagic complications, specificity for fresh thrombus, low index of reocclusion, sustained late patency, and reasonable cost ${ }^{163}$.

The best available treatment for AMI is the early and immediate administration of the thrombolytic agent to all patients without contraindication, who seek the emergency room within 12 hours of symptom onset and have ST segment elevation or complete left bundle branch block, unless mechanical recanalization with coronary angioplasty is being considered to be safely initiated within 90 minutes of hospital arrival ${ }^{163}$.

\section{Coronary angioplasty}

Coronary angioplasty can be used after thrombolysis failure or after successful thrombolysis to treat severe residual stenosis despite normal flow at rest. Angioplasty after unsuccessful thrombolysis, also known as rescue coronary angioplasty, was assessed in several small observational studies ${ }^{164}$. Even though the success index of the procedure in restoring flow was $80 \%$, the reocclusion index was $18 \%$ and mortality $10.6 \%$. Considering these results, the RESCUE Study ${ }^{165}$ was carried out. It randomized patients with anterior infarction treated with thrombolysis, without evidence of recanalization, for clinical conservative treatment and to rescue angioplasty. This study showed reduction of the composite endpoint of death and heart failure, in the group treated with angioplasty $(16.4 \%$ versus $6.5 \%, \mathrm{p}=0.05)$. This difference was not statistically significant in view of the low statistical power of the sample in detecting a difference that could be clinically significant. Therefore, despite lack of evidence based on a large-scale randomized clinical trial, rescue angioplasty has been the standard treatment when thrombolysis fails and angioplasty is available.

The verification that the reduced mortality obtained through thrombolysis is primarily related to its capacity for early and thorough recanalization, and the evidence that this occurs in more than half the patients treated with thrombolysis added to the fact that half of the patients are not eligible for thrombolysis, stimulated the investigation of mechanical recanalization through coronary angioplasty, an option denominated direct or primary angioplasty in AMI.

Several small observational series verified an important reduction in mortality with primary angioplasty, leading to three randomized studies conducted and published simultaneously ${ }^{166-168}$. These studies, which randomized 804 patients, compared different thrombolytic regimens with primary angioplasty in AMI and showed that mechanical recanalization offers a significant reduction in mortality $(2.5 \%$ versus $6.4 \%, \mathrm{p}<0.008)$, in infarction recurrence $(2.0 \%$ versus $7.9 \%, \mathrm{p}<0.001)$, in ischemia recurrence $(10.6 \%$ versus $31.4 \%$, $\mathrm{p}<0.0001)$, and in stroke $(0.3 \%$ versus $2.5 \%, \mathrm{p}<0.007){ }^{169}$. As these were small-scale studies, carried out in centers of 
excellence in interventional cardiology, and none of them used the thrombolytic regimen considered the gold standard (accelerated t-PA), there was a considerable questioning in regard to the possibility of generalizing these results to common hospital institutions that had interventional cardiology services. This is a crucial point because AMI has a highly prevalent occurrence, causing 1.5 million to 2.0 million hospital admissions yearly all around the world. Based on these premises, GUSTO IIb was designed, randomizing 1,138 patients in 57 centers. In this study, the index of normal flow obtainment (TIMI III) was $73 \%$, quite inferior to the indexes $>90 \%$ reported in the first three studies. The main analyzed variables showed statistically nonsignificant reductions of mortality $(5.7 \%$ versus $7.0 \%, \mathrm{p}=0.37)$, of the infarction recurrence index $(4.5 \%$ versus $6.5 \%, \mathrm{p}=0.13)$, and of stroke $(0.2 \%$ versus $0.9 \%, \mathrm{p}=0.11)$. When considered altogether, however, these variables occured less frequently with coronary angioplasty $(9.6 \%$ versus $13.7 \%, \mathrm{p}=0.03)$.

In the most comprehensive available metanalysis comprising 10 randomized studies and 2,606 patients, Weaver et al ${ }^{170}$ observed that primary angioplasty can be superior to thrombolysis because it offers lower mortality rate $(4.4 \%$ versus $6.5 \%, \mathrm{p}=0.02)$, associated with a lower recurrence of infarction $(7.2 \%$ versus $11.9 \%, \mathrm{p}<0.001)$, and a lower incidence of cerebral hemorrhage.

However, despite the higher efficiency of primary angioplasty evidenced in small and moderate randomized studies and in metanalysis, two registries, NRMI-2 ${ }^{171}$ and MITI $^{172}$, did not confirm these results, even though the analysis comprised around 30000 patients, $20 \%$ of whom were treated with angioplasty and the remaining with thrombolysis. Mortality in NRMI- 2 was $5.4 \%$ versus $5.2 \%$, and in MITI it was $5.6 \%$ versus $5.5 \%$ for angioplasty and thrombolysis, respectively.

Therefore, we can conclude that both recanalization methods still present important limitations. Thrombolysis is limited due to the following reasons: it restores normal flow in little more than half of the patients treated; only half of the patients are eligible for this treatment; fatal or disabling cerebral hemorrhage occurs in $1 \%$ of the patients treated this way; and there is a high index of recurrence of infarction and ischemia with this type of treatment. On the other hand, angioplasty is limited for the following reasons: it is not widely available (catheterization laboratories exist in $20 \%$ of the North American hospitals, $10 \%$ of the European hospitals, and $2 \%$ of the Brazilian hospitals); when available, there is a delay of more than two hours for the beginning of the procedure; there is infarction recurrence in 3-5\% of the cases; there is recurrence of ischemia in $10-15 \%$ of the cases; there is angiographic restenosis in $30-50 \%$ of the cases; the target vessel needs revascularization in six months in $20 \%$ of the cases; there is a great variability among operators and institutions.

Therefore, these limitations provide great opportunities for research with the two methods of recanalization aiming to treat the highest number of patients, in the smallest period of time, reducing immediate and mediate mortality and morbidity. The clinical research lines concentrate in three areas: search for the ideal thrombolytic agent and regimen; improvement of primary percutaneous revascularization by the use of stents and adjunct use of platelet glycoprotein IIbIIIa inhibitors; combination of thrombolysis and mechanical revascularization.

The main studies involving the new thrombolytic agents have already been mentioned. However, the newest concept in chemical revascularization is the association of thrombolytic agents in low doses with the potent platelet glycoprotein IIbIIIa inhibitors. The clinical exploration of this concept aims to make recanalization happen earlier, increase the recanalization index, promote a sustained recanalization, reduce the incidence of cerebral hemorrhage, and enable an earlier angioplasty to treat the postthrombolysis residual stenosis. Three pilot studies of efficiency and safety are in the final phase of analysis. The preliminary data have been positive in showing that a low dose of t-PA and abciximab (TIMI 14), a low dose of r-PA and abciximab (SPEED Trial or GUSTO IV Pilot), integrilin with a low dose of t-PA (INTRO AMI) produced recanalization indexes equal or superior to those obtained with the conventional dose of the thrombolytic agent, without increasing hemorrhagic complications. Therefore, these studies demonstrated that platelet glycoprotein IIbIIIa inhibition facilitates thrombolysis. Taking this into account, a study comprising 17000 patients will compare two thrombolysis regimens ( $\mathrm{r}-\mathrm{PA}$ in conventional dose and r-PA in half of the conventional dose associated with abciximab) having as its main goal the analysis of 30-day mortality. This study is GUSTO IV AMI and has its recruiting phase planned for the beginning of 1999.

The improvement of primary mechanical revascularization has involved the use of primary stent with or without abciximab, the most exhaustively clinically tested inhibitor of platelet glycoprotein IIbIIIa, so far. The use of primary stent in infarction was tested in several small studies, such as FRESCO ${ }^{173}$, GRAMI ${ }^{174}$, PASTA ${ }^{175}$, Stent PAMI Pilot ${ }^{176}$, and the study of Suryapranata et al ${ }^{177}$. Hospital and sixmonth results have proved the superiority of the stent in relation to angioplasty, especially for reducing the recurrence of infarction, the recurrence of ischemia, and the revascularization of the target vessel. The Stent PAMI Study, which randomized around 900 patients for the two techniques of mechanical recanalization, is in its final phase of analysis. The other investigation line of mechanical revascularization is its association with abciximab, and the Controlled Abciximab and Device Investigation to Lower Late Angioplasty Complications (CADILLAC) Study is in its recruiting phase of the 2,000 expected patients, who will be randomized into four groups to compare angioplasty versus stent, with and without the use of abciximab. Another ongoing study is the Abciximab Before Direct Angioplasty and Stenting in Myocardial Infarction Regarding Acute and Long-term Follow-up (ADMIRAL).

The most recent reperfusion strategy under study is the association of thrombolysis and mechanical recanalization. This strategy aims to maintain the advantage of easy 
and immediate administration of the thrombolytic agent in low dose, followed by angiography to document the state of flow and anatomical stratification. If the flow is adequate, the dose of the thrombolytic agent is completed and the patient is maintained under clinical treatment for six weeks, when an evaluation with an ischemic test is performed. If the flow is inadequate by angiography, angioplasty is performed. This study is called Plasminogen Activator Angioplasty Compatibility Trial (PACT), and its preliminary results have shown significant benefits in the preservation of the ventricular function.

Despite the unquestionable importance of the early and long-lasting flow obtainment in the infarction-related artery, more specific technologies to evaluate myocardial perfusion have shown that there often is dissociation between epicardial flow restoration and myocardial perfusion. Among these technologies we can cite: speed of resolution of the elevation of the ST segment ${ }^{178}$, invasive measurement of the flow speed with Doppler wire ${ }^{179}$, positron emission tomography ${ }^{180}$, contrast echocardiogram with microbubbles ${ }^{181,182}$. The extreme of that phenomenon is known as no-reflow phenomenon and it uncommonly complicates coronary angioplasty.

\section{Conclusion}

The recent advances in vascular biology and the findings of early coronary angiography and angioscopy have allowed the establishment of the erosion or rupture of a silent atherosclerotic plaque as the common denominator in AISs, independent from its degree of stenosis. The plaque complication depends on extrinsic and intrinsic factors, and often, but not consistently, results in subocclusive or temporary occlusive coronary thrombosis, which leads to unstable angina or non-Q MI. When the coronary thrombosis is occlusive and long-lasting, the clinical repercussion is AMI. The difference between unstable angina and AMI is the extension of the plaque rupture and subsequent degree of thrombosis.

Unstable angina treatment aims to control the thrombosis process with antithrombotic agents and to reestablish the balance between oxygen supply and consumption with antiischemic agents. The antithrombotic agents, either the antiplatelet ones (acetylsalicylic acid, ticlopidine, or platelet glycoprotein IIbIIIa inhibitors) or the antithrombotic ones (unfractioned or low-molecular-weight heparin) are administered to avoid the progression to long-lasting occlusive thrombosis and consequent MI or death. The antiischemic agents (nitrates, beta-blockers, or calcium antagonists) are administered to abolish or treat the anginal crises.

AMI treatment aims at the immediate and stable reestablishment of the flow in the infarction-related artery. The most used therapeutical option to coronary recanalization is the intravenous administration of thrombolytic agents (streptokinase, TPA, or r-PA). Thrombolysis is effective in half of the patients and its main complication is the rare occurrence of fatal or disabling cerebral hemorrhage. In addition, the early or late reocclusion is frequent. The alternative to chemical recanalization is mechanical recanalization with primary angioplasty. Angioplasty is more effective than thrombolysis in reestablishing a thorough and more stable recanalization; however, it is less available and has logistical limitations in treating a disease with such a high prevalence as AMI.

\section{References}

1. Enos WF, Holmes RH, Beyer J. Coronary disease among United States soldiers killed in action in Korea. JAMA 1953; 152: 1090-3.

2. Muller JE, Abela GS, Nesto RW, Tofler GH. Triggers, acute risk factors and vulnerable plaques: a new lexicon of a new frontier. J Am Coll Cardiol 1994; 23: 809-13.

3. Falk E, Sahh PK, Fuster V. Coronary plaque disruption. Circulation 1995; 92 : 627-71.

4. Mann JM, Davies MJ. Vulnerable plaque. Relation of characteristics to degree of stenosis in human coronary arteries. Circulation 1996; 94: 928-31.

5. Davies MJ. Stability and instability: the two faces of coronary atherosclerosis. Paul Dudley White Lecture, 1995. Circulation 1996; 94: 2013-20.

6. Abela GS, Picon PD, Friedl SE, et al. Triggering of plaque disruption and arterial thrombosis in an atherosclerotic rabbit model. Circulation 1995; 91: 776-84.

7. Muller JE, Toffler GH, Stone PH. Circadian variation and triggers of onset of acute cardiovascular disease. Circulation 1989; 79: 733-43.

8. Kono T, Morita H, Nishina T, et al. Circadian variations of onset of acute myocardial infarction and efficacy of thrombolytic therapy. J Am Coll Cardiol 1996; $27: 774-8$.

9. Willich SN, Collins R, Peto R, et al. Morning peak in the incidence of myocardial infarction: experience in the ISIS-2. Eur Heart J 1992; 13: 594-8.

10. Gnecchi-Ruscone T, Piccaluga E, Guzzeti S, Contini M, Montano N, Nicolis E. Morning and Monday: critical periods for the onset of acute myocardial infarction: the GISS 2 Study experience. Eur Heart J 1994; 15: 882-7.

11. Willich SN, Lowel H, Lewis M, Hormann A, Arntz HR, Keil U. Weekly variation of acute myocardial infarction. Increased Monday risk in the working population. Circulation 1994; 90: 87-93.
12. Ornato JP, Siege L, Craren EJ, Nelson N. Increased incidence of cardiac death attributed to acute myocardial infarction during winter. Coron Art Dis 1990; 1: 199-203.

13. Douglas AS, al Sayer H, Rawles JM, Allan TM. Seasonality of disease in Kuwait. Lancet 1991; 337: 1393-7.

14. Gabbay FH, Krantz DS, Kop WJ, et al. Triggers of myocardial ischemia during life in patients with coronary artery disease: physical and mental activities, anger and smoking. J Am Coll Cardiol 1996; 27: 585-92.

15. Mitleman MA, Maclure M, Sherwood JB, et al. Triggering of acute myocardial infarction by episodes of anger. Circulation 1995; 92: 1720-5.

16. Mittleman MA, Maclure M, Tofler GH, Sherwood JB, Goldberg RJ, Muller JE Triggering of acute myocardial infarction by heavy physical exertion. Protection against triggering by regular exertion. Determinants of Myocardial Infarction Onset Study Investigators. N Engl J Med 1993; 329: 1677-83.

17. Willich SN, Lewis M, lowel H, Arntz HR, Schubert F, Schroder R. Physical exertion as a trigger of acute myocardial infarction. N Engl J Med 1993; 329: 1684-90.

18. Leor J, Kloner RA. The Northridge earthquake as a trigger for acute myocardial infarction. Am J Cardiol 1996; 77: 1230-2.

19. Richardson PD, Davies MJ, Born GVR. Influence of plaque configuration and stress distribution on fissuring of coronary atherosclerotic plaques. Lancet 1989; 2: 941-4.

20. Lendon CL, Davies MJ, Born GV, Richardson PD. Atherosclerotic plaque caps are locally weakened when macrophages density is increased. Atherosclerosis 1991; 87: 87-90. 
21. Lendon CL, Davies MJ, Richardson, PD, Born GV. Testing of small connective tissue specimens for the determination of the mechanical behavior of atherosclerotic plaques. J Biomed Eng 1993; 15: 27-33.

22. Lee RT, Loree HM, Cheng GC, Lieberman EH, Jaramillo N, Schoen FJ. Computational structural analysis based on intravascular ultrasound imaging before in vitro angioplasty: prediction of plaque fracture locations. J Am Coll Cardiol 1993; $21: 777-82$.

23. Cheng GC, Loree HM, Kamm RD, Fishbein MC, Lee RT. Distribution of circumferential stress in ruptured and stable atherosclerotic lesions: a structural analysis with histopathologic correlation. Circulation 1993; 87: 1179-87.

24. LoreeHM, KammRD, Stringfellow RG,LeeRT. Effects of fibrous cap thickness on peak circumferential stress in model atherosclerotic vessels. Circ Res 1992; 71: 850-8

25. Lee RT, Richardson SG, Loree HM, et al. Prediction of mechanical properties of human atherosclerotic tissue by high-frequency intravascular ultrasound imaging. An in vitro study. Arteriosclerosis Thrombosis 1992; 12: 1-5.

26. Thompson SG, Kienast J, Pyke SD, Harverkate F, Van LJ. Hemostatic factors and the risk of myocardial infarction or sudden death in patients with angina pectoris. European Concerted Action on Thrombosis and Disabilities Angina Pectoris Study Group. N Engl J Med 1995; 332: 635-41.

27. Humphries SE, Green FR, Temple A, et al. Genetic factors determining thrombosis and fibrinolysis. Na Epidemiol 1992; 2: 371-85.

28. Eriksson P, Kallin B, vant't Hooft F, Bavenholm P, Hamsten. Allele-specific increase in basal transcription of the plasminogen-activator inhibitor 1 gene is associated with myocardial infarction. Proc Natl Academy Sci USA 1995; 92: 1851-5.

29. Wilcox JN, Smith KM, Schwartz SM, Gordon D. Localization of tissue factor in the normal vessel wall and in the atherosclerotic plaque. Proc Natl Acad Sci USA 1989; 86: 2839-43.

30. Moreno PR, Bernardi VH, Lopez-Cuellar J, et al. Macrophages, smooth muscle cells, and tissue factor in unstable angina. Implications for cell-mediated thrombogenicity in acute coronary syndromes. Circulation 1996; 94: 3090-7.

31. Van der Wal AC, Becker AE, van der Loos CM, Das PK. Site of intimal rupture or erosion of thrombosed coronary atherosclerotic plaques is characterized by an inflammatory process irrespective of the dominant plaque morphology. Circulation 1994; 89: 36-44

32. Davies MJ. Stability and instability: the two faces of coronary atherosclerosis. Paul Dudley White Lecture, 1995. Circulation 1996; 94: 2013-20.

33. Gertz SD, Roberts WC. Hemodynamics shear force in rupture of coronary arterial atherosclerotic plaques. Am J Cardiol 1990; 66: 1368-72.

34. Davies MJ, Richardson PD, Woolf N, Katz DR, Mann J. Risk of thrombosis in human atherosclerotic plaques: role of extracellular lipid, macrophage, and smooth muscle cell content. Br Heart J 1993; 69: 377-81.

35. Falk E. Plaque rupture with severe pre-existing stenosis precipitating coronary thrombosis. Characteristics of coronary atherosclerotic plaques underlying fatal occlusive thrombi. Br Heart J 1983; 50: 127-34

36. Geng Y-J, Libby P. Evidence for apoptosis in advanced human atheroma. Co-localization with interleukin-1 beta-converting enzyme. Am J Pathol 1995; 147: 251-66.

37. Kovanen P, Kaartinen M, Paavonen T. Infiltrates of activated mast cells at the site of coronary atheromatous erosion or rupture in myocardial infarction. Circulation 1995; 92: 1084-8

38. Burleigh MC, Brigs AD, Lendon CL, Born GV, Richardson PD. Collagen types I and III, collagen content, GAGs and mechanical strength of human atherosclerotic plaque caps: span-wise variations. Atherosclerosis 1992; 96: 71-81.

39. Libby P. The molecular bases of the acute coronary syndromes. Circulation 1995; 91: 2844-50.

40. Galis Z, Sukhova G, Lark M, Libby P. Increased expression of matrix metalloproteinases and matrix degrading activity in vulnerable regions of human atherosclerotic plaques. J Clin Invest 1994; 94: 2493-503.

41. Shah PK, Falk E, Badimon JJ, Henney AM, Wakeley PR, Davies MJ. Localization of stromelysin gene expression in atherosclerotic plaques by in situ hybridization. Proc Natl Acad Sci USA 1991; 88: 8154-8.

42. Shah PK, Falk E, Badimon JJ, et al. Human monocyte-derived macrophages induce collagen breakdown in fibrous caps of atherosclerotic plaques. Potential role of matrix-degrading metalloproteinases and implications for plaque rupture. Circulation 1995; 92: 1565-9.

43. Gordon D, Schwartz SM. Replication of arterial smooth muscle cells in hypertension and atherosclerosis. Am J Cardiol 1987; 59: 44A-8A.

44. Clowes AW, Reidy MA. Prevention of stenosis after vascular reconstruction: pharmacologic control of intimal hyperplasia - a review. J Vasc Surg 1991; 13: 885-91.

45. Hansson GK, Jonasson L, Holm J, Clowes MK, Clowes A. Interferon gamma regulates vascular smooth muscle proliferation and expression in vivo and in vitro. Circ Res 1988; 63: 712-9.

46. Hansson GK, Hellstrand M, Rymo L, Rubbia L, Gabbiani G. Interferon gamma inhibits both proliferation and expression of differentiation-specific alpha-smooth muscle actin in arterial smooth muscle cells. J Exp Med 1989; 170: 1595-608.

47. Waner SJC, Friedman GB, Libby P. Immune interferon inhibits proliferation and induces 2-5 oligoadenylate synthetase gene expression in human vascular smooth muscle cells. J Clin Invest 1989; 83: 1174-82.
48. Geng Y-J, Wu Q, Muszynski M, Hansson G, Libby P. Apoptosis of vascular smooth muscle cells induced by in vitro stimulation with interferon gamma, tumor necrosis factor-alpha, and interleukin-1-beta. Arterioscler Thromb Vasc Biol 1996; 16: 19-27.

49. Bager AC, Beeuwkes R III, Lainey LL, Silverman KJ. Hypothesis: vasa vasorum and neovascularization of human coronary arteries. A possible role in the pathophysiology of atherosclerosis. N Engl J Med 1984; 319: 175-7.

50. Paterson JC. Capillary rupture with intimal hemorrhage as a causative factor in coronary thrombosis. Arch Pathol 1938; 25: 474-87.

51. Leary T. Coronary spasm as a possible factor in producing sudden death. Am Heart J 1934; 10: 338-44.

52. Lin CS, Penha PD, Zak FG, Lin JC. Morphodynamic interpretation of acute coronary thrombosis, with special reference to volcano-like eruption of atheromatous plaque caused by coronary artery spasm. Angiology 1988; 39: 535-47.

53. Bogaty P, Hackett D, Davies G, Maseri A. Vasoreactivity of the culprit lesion in unstable angina. Circulation 1994; 90: 5-11

54. Lam JY, Chesebro JH, Steele PM, Badimon L, Fuster V. Is vasospasm related to platelet deposition? Relationship in a porcine preparation of arterial injury in vivo. Circulation 1987; 75 : 243-8.

55. Kaski JC, Tousoulis D, McFadden E, Crea F, Pereira WI, Maseri A. Variant angina pectoris. Role of coronary spasm in the development of fixed coronary obstructions. Circulation 1992; 85: 619-26.

56. Davies MJ, Bland JM, Hangartner JR, Angelini Thomas AC. Factors influencing the presence or absence of acute coronary artery thrombi in sudden ischemic death. Eur Heart J 1989; 10: 203-8.

57. Frink RJ. Chronic ulcerated plaques: new insights into the pathogenesis of acute coronary disease. J Invas Cardiol 1994; 6: 173-85.

58. Fernandez Ortiz A, Badimon JJ, Falk E, et al. Characterization of the relative thrombogenicity of atherosclerotic plaque components: implications for consequences of plaque rupture. J Am Coll Cardiol 1994; 23: 1562-9.

59. Van Zanten GH, de Graaf S, Slootweg PJ, et al. Increased platelet deposition on atherosclerotic coronary arteries. J Clin Invest 1994; 93: 615-32.

60. Annex BH, Denning SM, Channon KM, et al. Differential expression of tissue factor protein in directional atherectomy specimens from patients with stable angina and unstable coronary syndromes. Circulation 1995; 91: 619-22.

61. Ruggeri ZM. Mechanisms of shear-induced platelet adhesion and aggregation. Thromb Haemostas 1993; 70: 119-23.

62. Merino A, Cohen M, Badimon JJ, Fuster V, Badimon L. Synergistic action of severe wall injury and shear forces on thrombus formation in arterial stenosis: definition of a thrombotic shear rate threshold. J Am Coll Cardiol 1994; 24: 1091-7.

63. White HD, French JK, Hamer AW, et al. Frequent reocclusion of patent infarctedrelated arteries between 4 weeks and 1 year: effect of antiplatelet therapy. J Am Coll Cardiol 1995; 25: 218-23.

64. Lam JY, Latour JG, Lesperance J, Watters D. Platelet aggregation, coronary artery disease progression and future coronary events. Am J Cardiol 1994; 73: 333-8.

65. Fuster V, Lewis A. Conner Memorial Lecture: Mechanisms leading to myocardial infarction: insights from studies of vascular biology. Circulation 1994; 90: 2126-46.

66. Meade TW, Ruddock V, Stirling Y, Chakrabarti R, Miller GJ. Fibrinolytic activity, clotting factors, and long-term incidence of ischemic heart disease in the Northwick Park Heart Study. Lancet 1993; 342: 1076-9.

67. Wilhelmsen L. Thrombocytes and coronary heart disease. Circulation 1991; 84: 936-8.

68. Cairns J, Theroux $\mathrm{P}$, Armstrong $\mathrm{P}$, et al. Unstable angina: report from a Canadian expert roundtable. Can J Cardiol 1996; 12: 1279-92.

69. Maseri A, L'Abbate A, Barodi G, et al. Coronary vasospasm as a possible cause of myocardial infarction: a conclusive derived from the study of preinfarction angina. N Engl J Med 1978; 299: 1272-7.

70. Rizik DG, Healy S, Margulis A, et al. A new classification for hospital prognosis of unstable angina pectoris. Am J Cardiol 1995; 75: 993-7.

71. Braunwald E. Unstable angina. A classification. Circulation 1989; 80: 410-4.

72. Ahmed W, Bitl JA, Braunwald E. Relation between clinical presentation and angiographic morphology in unstable angina pectoris. Am J Cardiol 1988; 62: 1024-7.

73. Moliterno D, Aguirre F, Cannon C, et al. The global unstable angina registry and treatment evaluation. Circulation 1996; 94: I-95.

74. Falk E. Unstable angina with fatal outcome: dynamic coronary thrombolysis leading to infarction and/or sudden death. Circulation 1985; 71: 699-708.

75. Moise A, Theoroux $\mathrm{P}$, Tayemans $\mathrm{Y}$, et al. Unstable angina and progression of coronary atherosclerosis. N Engl J Med 1983; 309: 685-9.

76. Fuster V, Badimon JJ, Chesebro JH. The pathogenesis of coronary artery disease and acute coronary syndromes. N Engl J Med 1992; 326: 242-50.

77. Willerson JT, Golino P, Eidt J, Campbell WB, Buja LM. Specific platelet mediators and unstable coronary artery lesions: experimental evidence and potential clinical implications. Circulation 1989; 80: 198-205.

78. Ryan TJ, Anderson JL, Antman, et al. ACC/AHA guidelines for the management of patients with acute myocardial infarction: Executive summary. A report of the 
American College of Cardiology/ American Heart Association Task Force on Practice Guidelines (Committee on Management of Acute Myocardial Infarction). Circulation 1996; 94: 2341-50.

79. Mehta D, Cuwin J, Gomes A, Fuster V. Sudden death in coronary artery disease: acute ischemia versus myocardial substrate. Circulation 1997; 96: 3215-23.

80. Lefkovits J, Plow EF, Topol EL. Platelet glycoprotein IIbIIIa receptors in cardiovascular medicine. N Engl J Med 1995; 332: 1553-9.

81. Sherman CT, Litvak F, Grundfest W, et al. Coronary angioscopy in patients with unstable angina pectoris. N Engl J Med 1986; 315: 913-9.

82. Wilensky R, Bourdillon P, Vix V, Zeller J. Intracoronary artery thrombus formation in unstable angina: a clinical, biochemical and angiographic correlation. J Am Coll Cardiol 1993; 21: 692-9.

83. Thíeroux P, Latour J, leger-Gauthier C, DeLara J. Fibrinopeptide A and platelet factor levels in unstable angina pectoris. Circulation 1987; 75: 156-62.

84. Kruskal J, Commerford P, Franks J, Kirsch R. Fibrin and fibrinogen-related antigens in patients with stable and unstable coronary artery disease. N Engl J Med 1987; 309: 1361-65.

85. Zalewski A, Shi Y, Nardone D, et al. Evidence for reduced fibrinolytic activity in unstable angina at rest. Circulation 1991; 83: 1685-91.

86. Fitzgerald DJ, Roy L, Catella F, Fitzgerald GA. Platelet activation in unstable coronary disease. N Engl J Med 1986; 315: 983-9.

87. Alexopoulos D, Ambrose JA, Stump D, et al. Thrombosis-related markers in unstable angina pectoris. J Am Coll Cardiol 1991; 17: 866-71.

88. Theroux P, Liddon R-M. Unstable angina pathogenesis, diagnosis and treatment. Curr Prob Cardiol 1993; 335: 775-82.

89. American Heart Association - Heart and Stroke Facts: 1996 Statistical Supplement. Dallas, American Heart Association, 1996; 1-23.

90. Braunwald E, Jones RJ, Mark DB, et al. From the US Department of Health and Human Services, Public Health Service, Agency for Health Care Policy and Research, National Heart, Lung and Blood Institute. Circulation 1994; 90: 613-22.

91. Muller-Bardorf M, Frietag H, Scheffold T, Remppis A, Kubler W, Katus HA. Development and characterization of a rapid assay for bedside determinations of cardiac troponin T. Circulation 1995; 92: 2869-75.

92. Lindahl B, Venge P, Wallentin L, for the FRISC Study Group. Relation between troponin $\mathrm{T}$ and the risk of subsequent cardiac events in unstable coronary artery disease. Circulation 1996; 93: 1651-7.

93. Luscher M, Ravkilde J, Thygesen K. Troponin $\mathrm{T}$ and $\mathrm{I}$ in the detection of myocardial damage and subsequent events in 491 consecutive chest pain patients. A substudy of the TRIM trial. Circulation 1996; 94(suppl I): I-323.

94. DeWood MA, Spores J, Notske R, Mouser LT, Burroughs R, Golden MS, Lang HT. Prevalence of total coronary occlusion during the early hours of transmural myocardial infarction. N Engl J Med 1980; 303: 897-902.

95. Ambrose JA, Tannembaum MA, Alexopoulos D, et al. Angiographic progression of coronary artery disease and the development of myocardial infarction. J Am Coll Cardiol 1988; 12: 56-62.

96. Luchi RJ, Scott SM, Deupree RH, et al. Comparison of medical and surgical treatment for unstable angina pectoris. N Engl J Med 1987; 316: 977-84.

97. CASS Principal Investigators and their associates. Myocardial infarction and mortality in the Coronary Artery Surgery Study (CASS) randomized trial. N Engl J Med 1984; 310: 750-8.

98. Alison HW, Russell ROJ, Mantle JA, Kouchoukos NT, Moraski RE, Rakley CE. Coronary anatomy and arteriography in patients with unstable angina pectoris. Am J Cardiol 1978; 41: 204-9.

99. TIMI IIIA Investigators - Early effects of tissue-type plasminogen activator added to conventional therapy on the culprit coronary lesion in patients presenting with ischemic cardiac pain at rest: results of the Thrombolysis Inhibition in Myocardial Ischemia (TIMI IIIA) Trial. Circulation 1993; 87: 38-52.

100. Vetrovec GW, Cowley MJ, Overton H, Richardson DW. Intracoronary thrombus in syndromes of unstable myocardial ischemia. Am Heart J 1981; 102: 1202.

101. Freeman MR, Williams AE, Chisholm RJ, Armstrong PW. Intracoronary thrombus and complex morphology in unstable angina. Circulation 1989; 80: 17-23.

102. Capone G, Wolf NM, Meyer B, Meister SG. Frequency of intracoronary filling defects by angiography in angina pectoris at rest. Am J Cardiol 1985; 56: 403-6.

103. Gotoh K, Minamino T, Katoh O, et al. The role of intracoronary thrombus in unstable angina: angiographic assessment and thrombolytic therapy during ongoing anginal attacks. Circulation 1988; 77: 526-34.

104. Fibrinolytic Therapy Trialistsí (FTT) Collaborative Group. Indications for fibrinolytic therapy in suspected acute myocardial infarction: collaborative overview of early mortality and major morbidity results from all randomized trials of more than 1,000 patients. Lancet 1994; 343:311-22.

105. Braunwald E, Jones RJ, Mark DB, et al. From the US Department of Health and Human Services, Public Health Service, Agency for Health Care Policy and Research, National Heart, Lung and Blood Institute - Diagnosing and Managing Unstable Angina. Circulation 1994; 90: 613-22.

106. Jugdutt BI, Warnica JW. Tolerance with low dose of intravenous nitroglycerin therapy in acute myocardial infarction. Am J Cardiol 1989; 64: 581.
107. Theroux P, Tayemans Y, Morissette D, et al. A randomized study comparing propranolol and diltiazem in the treatment of unstable angina. J Am Coll Cardiol $1985 ; 5: 717$.

108. Lubsen J, Tijssen JGP for the HINT Research Group - Efficacy of nifedipine and metoprolol in the treatment of unstable angina in the corornary care unit: findings from the Holland Interuniversity Nifedipine/Metoprolol Trial (HINT) Am J Cardiol 1987; 60: 18A -25A.

109. TIMI IIIB Investigators - Effects of tissue-type plasminogen activator and a comparison of early invasive and conservative strategies in unstable angina and non-Q-wave myocardial infarction: results of the TIMI IIIB trial. Circulation 1994; 89: 1545

110. Theroux P, Ouimet H, McCans J, et al. Aspirin, heparin, or both to treat acute unstable angina. N Engl J Med 1988; 319: 1105-11.

111. The RISC Group - Risk of myocardial infarction and death during treatment with low dose aspirin and intravenous heparin in men with unstable coronary artery disease. Lancet 1990; 336: 827-30.

112. Lewis HDJ, Davis JW, Archibald DG, et al. Protective effects of aspirin against acute myocardial infarction and death in men with unstable angina. N Engl J Med 1983; 309: 396-403.

113. Cairns JA, Gent M, Singer J, et al. Aspirin, sulfinpyrazone, or both in unstable angina. N Engl J Med 1985; 313: 1369-75.

114. Balsano F, Rizzon P, Violi F, et al and the Studio della Ticlopidina nellíAngina Instable Group - Antiplatelet treatment with ticlopidine in unstable angina: a controlled multicenter clinical trial. Circulation 1990; 825: 17-26.

115. Narins CR, Topol E. Attention shifts to the white clot. Lancet 1997; 350(suppl III): 2 .

116. The EPIC Investigators - Use of monoclonal antibody directed against the platelet glycoprotein IIbIIIa receptor in high-risk coronary angioplasty. N Engl J Med 1994; 330: 956-61.

117. The EPILOG Investigators - Platelet glycoprotein IIbIIIa receptor blockade and low-dose heparin during percutaneous coronary revascularization. N Engl J Med 1997; 336: 1689-96

118. The CAPTURE Investigators - Randomized placebo-controlled trial of abciximab before and during coronary intervention in refractory unstable angina: The CAPTURE Study. Lancet 1997; 349: 1429-35.

119. The Platelet Receptor Inhibition in Ischemic Syndrome Management in Patients Limited by Unstable Signs and Symptoms (PRISM-PLUS) Study Investigators. Inhibition of the platelet glycoprotein IIbIIIa receptor with tirofiban in unstable angina and non-Q-wave myocardial infarction. N Engl J Med 1998; 338: 1488-97.

120. The PURSUIT Trial Investigators - Inhibition of platelet glycoprotein IIbIIIa with eptifibatide in patients with acute coronary syndromes. N Engl J Med 1998; 339: 436-43.

121. The RESTORE Investigators - Effects of platelet glycoprotein IIbIIIa blockade with tirofiban on adverse cardiac events in patients with unstable angina or acute myocardial infarction undergoing coronary angioplasty. Circulation 1997; 96: 1445-53.

122. The Glogbal Use of Strategies to Open Occluded Coronary Arteries IIb Investigators - A comparison of recombinant hirudin with heparin for the treatment of acute coronary syndromes. N Engl J Med 1996; 335: 775-82.

123. Cohen M, Adams PC, Parry G, et al for the Antithrombotic Therapy in Acute Coronary Syndromes research Group - Combination antithrombotic therapy in unstable rest angina and non-Q-wave infarction in non prior aspirin users. Circulation 1994; 89: 81-8

124. Oler A. Adding heparin to aspirin reduces the incidence of myocardial infarction and death in patients with unstable angina: a metaanalysis. JAMA 1996; 2276: 811-15.

125. The FRISC Study Group - Low-molecular-weight heparin during instability in coronary artery disease. Lancet 1996; 347:561-8.

126. Cohen M, Demers C, Gurfinkel EP, et al, for the Efficacy and Safety of Subcutaneous Enoxiparin in Non-Q-Wave Coronary Events Study Group - Lowmolecular-weight heparin versus unfractioned heparin for unstable angina and non-Q-wave myocardial infarction. N Engl J Med 1997; 337: 447-52.

127. The Global Use of Strategies to Open Occluded Coronary Arteries IIa Investigators - Randomized trial of intravenous heparin versus recombinant hirudin for acute coronary syndrome. Circulation 1994; 90: 1631-37.

128. Organization to Assess Strategies for Ischemic Syndromes (OASIS) Investigators - Comparison of the effects of two doses of recombinant hirudin compared with heparin in patients with acute myocardial ischemia without ST elevation: a pilot study. Circulation 1997; 97: 769-77.

129. Hultgren HN, Pfeifer JF, Angel WW, Lipton MJ, Bilisoly J. Unstable angina: comparison of medical and surgical patients. Am J Cardiol 1977; 39: 734-40.

130. Boden WE, OíRourke RA, Crawford MH, et al for the The Veteran Affairs non-QWave Infarction Strategies in Hospital Study Group (VANQWISH) - Outcomes in patients with acute non-Q-wave myocardial infarction randomly assigned to an invasive as compared with a conservative management strategy. N Engl J Med 1998; 338: 1785-92. 
131. Pocock SJ, Henderson RA, Rickards AF, et al. Metanalysis of randomized trials comparing coronary angioplasty with bypass surgery. Lancet 1995; 346: 1184.

132. Bypass Angioplasty Revascularization Investigators - Comparison of coronary bypass surgery with angioplasty in patients with multivessel disease. $\mathrm{N}$ Engl J Med 1996; 335: 217.

133. Szatmary LJ, Marco J, Fajadet J, Caster C. The combined use of diastolic counterpulsation and coronary dilation in unstable angina due to multivessel disease under unstable hemodynamic conditions. Int J Cardiol 1988; 19: 59-66.

134. Rentroop KP, Blanke H, Karsch KR, et al. Acute myocardial infarction: intracoronary application of nitroglycerin and streptokinase. Clin Cardiol 1979; 2 : 354-63.

135. Reimer KA, Lowe JE, Rasmussen MM, Jennings RB. The wave-front phenomenon of ischemic death. I. Myocardial infarct size versus duration of coronarry occlusion in dogs. Circulation 1977; 56: 786-94

136. Pell S, Fayerweather WE. Trends in the incidence of myocardial infarction and in the associated mortality and morbidity in a large employed population, 19571983. N Engl J Med 1985; 312: 1005.

137. Rentrop KP. Restoration of anterograde flow in acute myocardial infarction: The first 15 years. J Am Coll Cardiol 1995; 25: 1S

138. TIMI Study Group - The Thrombolysis in Myocardial Infarction (TIMI) Trial: Phase I findings. N Engl J Med 1985; 312: 932-6.

139. Verstraete M, Bernard R, Bory M, et al. Randomized trial of intravenous recombinant-type plasminogen activator versus intravenous streptokinase in acute myocardial infarction. Report from the European Cooperative Study Group for recombinant Tissue-Type Plasminogen Activator. Lancet 1985; 1: 842-7.

140. GISSI II/International Study Group - In-hospital mortality and clinical course of 20,891 patients with suspected acute myocardial infarction randomized between alteplase and streptokinase with and without heparin. Lancet 1990; 336: 71-5.

141. ISIS-3 (Third International Study of Infarct Survival) Collaborative Group ISIS-3: a randomized comparison of streptokinase vs tissue plasminogen activator vs anistreplase and of aspirin plus heparin alone among 41,299 cases of suspected acute myocardial infarction. Lancet 1992; 339: 753-70.

142. GUSTO Investigators - An international randomized trial comparing four thrombolytic strategies for acute myocardial infarction. N Engl J Med 1993; 329: 673-82.

143. GUSTO Angiographic Investigators - The effects of tissue plasminogen activator, streptokinase, or both on coronary artery patency, ventricular function, and survival after acute myocardial infarction. N Engl J Med 1993; 329: 1615-22.

144. Simes RJ, Topol EJ, Homes DR Jr, et al. Link between the angiographic substudy and mortality outcomes in a large randomized trial of myocardial reperfusion. Importance of early and complete infarct artery reperfusion. Circulation 1995; 91: 1923-8.

145. Puma JA, Sketch MH Jr, Simes RJ, Morris DC, Topol EJ, Califf RM. Long-term impact of a patent infarct-related artery: 1-year survival in the GUSTO trial. J Am Coll Cardiol 1995; Special Issue $130 \mathrm{~A}$.

146. Anderson JL, Karagounis LA, Califf RM. Metaanalysis of five reported studies on the relation of early coronary patency grades with mortality and outcomes after acute myocardial infarction. Am J Cardiol 1996; 78: 1-8.

147. Reiner JS, Lundergan CF, Rohrbeck SC, et al. The impact on left ventricular function of coronary reocclusion after successful thrombolysis for acute myocardial infarction. J Am Coll Cardiol 1994; 23: 13A.

148. Martin GV, Kennedy JW. Choice of thrombolytic agent. In: Julian D, Braunwald E (eds). Management of Acute Myocardial Infarction. London: WB Saunders Ltd, 1994: 71.

149. Ohman EM, Califf RM, TopolEJ, et al and the TAMI Study Group-Consequences of reocclusion following successful reperfusion therapy in acute myocardial infarction. Circulation 1990; 82: 781-91.

150. Bleich SD, Nichols TC, SchumacherRR, CookeDH, TateDA, Teichman SL. Effect of heparin on coronary arterial patency after thrombolysis with tissue plasminogen activator in acute myocardial infarction. Am J Cardiol 1990; 1412-17.

151. Chesebro JH, Knatterud G, Roberts R, et al. Thrombolysis In Myocardial Infarction (TIMI), Phase I: a comparison between intravenous tissue plasminogen activator and intravenous streptokinase. Clinical findings through hospital discharge. Circulation 1987; 76: 142-54.

152. Van der Werf. Discrepancies between the effects of coronary reperfusion on survival and left ventricular function. Lancet 1989; 1: 1367-9.

153. Nasch J. The open infarct-related artery: Theoretical and practical considerations. Coron Art Dis 1995; 6: 739-49.

154. Kim CB, Braunwald E. Potential benefits of late reperfusion of infarcted myocardium. The open artery hypothesis. Circulation 1993; 88: 2416-36.

155. Braunwald E. Myocardium perfusion, limitation of infarct size, reduction of left ventricular dysfunction and improved survival. Should the paradigm be expanded? Circulation 1989; 79: 441-4

156. Califf RM, Topol EJ, Gersh BJ. From myocardial salvage in acute myocardial infarction: the role of reperfusion therapy. J Am Coll Cardiol 1989; 14: 1382-8.

157. Gang ES, Lew AS, Hong M, Wang FZ, Siebert CA, Peter T. Decreased incidence of ventricular late potentials after successful thrombolytic therapy for acute myocardial infarction. N Engl J Med 1989; 321: 712-6.
158. Sager PT, Perlmutter RA, Rosenfeld LE, McPherson CA, Wackers FJ, Batsford WP. Electrophysiologic effects of thrombolytic therapy in patients with a transmural anterior myocardial infarction complicated by left ventricular aneurysm formation. J Am Coll Cardiol 1988; 12: 19-24.

159. Hochman JS, Choo H. Limitation of myocardial infarct expansion by reperfusion independent of myocardial salvage. Circulation 1987; 75: 299-306.

160. Lavie CJ, O'Keefe JH, Chesebro JH, Clements IP, Gibbons RJ. Prevention of late ventricular dilatation after acute myocardial infarction by successful thrombolytic reperfusion. Am J Cardiol 1990; 66: 31-6.

161. White HD, Cross DB, Elliot JM, Norris RM, Yee TW. Long-term prognostic importance of patency of the infarct-related coronary artery after thrombolytic therapy for acute myocardial infarction. Circulation 1994; 89: 61-7.

162. Lamas GA, Flaker GC, Mitchel G, et al. Effect of infarct artery patency on prognosis after acute myocardial infarction. The Survival and Ventricular Enlargement Investigators. Circulation 1995; 92: 1101-9.

163. White HD, Van de Werf FJJ. Thrombolysis for acute myocardial infarction. Circulation 1998; 97: 1632-46.

164. Ellis SG, Van de Werf FJJ, Ribeiro da Silva E, Topol EJ. Present status of rescue coronary angioplasty: Current polarization of opinion and randomized trials. J Am Coll Cardiol 1992; 19: 681-6.

165. Grines CL, Browne KR, Marco J, et al. A comparison of primary angioplasty with thrombolytic therapy for acute myocardial infarction. N Engl J Med 1993; 328: 673-9.

166. Zijlstra F, de Boer MJ, Hoorntje, et al. A comparison of immediate coronary angioplasty with intravenous streptokinase in acute myocardial infarction. $\mathrm{N}$ Engl J Med 1993; 328: 680-4.

167. Gibbons RJ, Holmes DR, Reeder GS, et al. Immediate angioplasty compared with administration of a thrombolytic agent followed by conservative treatment for myocardial infarction. N Engl J Med 1993; 328: 685-91.

168. Stone GW. Primary Angioplasty in Acute Myocardial Infarction. In: Topol EJ Acute Coronary Syndromes. New York: Marcel Dekker, 1997: 233.

169. Stone GW. Primary Angioplasty in Acute Myocardial Infarction. In: Topol EJ, Acute Coronary Syndromes. New York: Marcel Dekker, 1997:223.

170. Weaver WD, Simes RJ, Betriu A, et al. Primary Coronary Angioplasty vs Thrombolysis Collaboration Group: Comparison of primary coronary angioplasty and intravenous thrombolytic therapy for acute myocardial infarction. JAMA 1997; 278: 2093-8.

171. Tiefenbrun C, et al, for the National Registry of Myocardial Infarction 2 - Clinical experience with PTCA compared with alteplase in acute myocardial infarction. J Am Coll Cardiol 1998; 31: 1260-5.

172. Every NR, Parsons LS, Hlatky M, et al, for the Myocardial Infarction Triage and Intervention Investigators - A comparison of thrombolytic therapy with primary coronary angioplasty. N Engl J Med 1996; 335: 1253-60.

173. Antoniucci D, Santoro GM, Bolognese L, et al, for the FRESCO Investigators Elective stenting in acute myocardial infarction. J Am Coll Cardiol 1998; 31 : 1234-9.

174. Rodrigues A, Fernandez M, Bernardi V, et al, for the GRAMI Investigators Coronary stents improve hospital results during coronary angioplasty in acute myocardial infarction. Am J Cardiol 1998; 81: 1286-91.

175. Saito S, Hosokawa G, Suzuki S, Nakamura S, for the Japanese PASTA Trial Study Group - Primary stent implantation is superior to balloon angioplasty in acute myocardial infarction. J Am Coll Cardiol 1997; 29(suppl A): 221A.

176. Stone GW. Primary Angioplasty in Acute Myocardial Infarction. In Topol EJ Acute Coronary Syndromes. New York: Marcel Dekker, 1997: 233.

177. Suryapranata H, Hoornttje JCA, de Boer M-J, Zijlstra. Randomized comparison of primary stenting with primary balloon angioplasty in acute myocardial infarction. Circulation 1998; 97: 2502-5.

178. Zeymer U, Schroder R, Lolhoek P, Tebbe U, Jessel A, Neuhaus K-L, for the HIT-4 Investigators - 90-minute patency, and 90-minute and 180-minute resolution of ST-segment elevation are equally effective predictors of 30-day mortality after thrombolysis in patients with acute myocardial infarction: results of the HIT-4 study. Circulation 1997; 96(suppl I): I-203.

179. Neuman F-J, Blasini R, Schmitt C, et al. Effect of glycoprotein IIaIIIb receptor blockade on recovery of coronary flow and left ventricular function after placement of coronary artery stents in acute myocardial infarction. Circulation 1998 (in press).

180. Maes A, VanderWerfF, Nuyts J, Bormans G, DesmetW, Mortelmans L. Impairedmyocardial tissue perfusion early after successful thrombolysis. Impact on myocardial flow, metabolism, and function at late follow-up. Circulation 1995; 92: 2072-8.

181. Ito H, Tomooka T, Sakai N, et al. Lack of myocardial perfusion immediately after successful thrombolysis. A predictor of poor recovery of left ventricular function in anterior myocardial infarction. Circulation 1992; 85: 1699-1705.

182. Ito H, Okamura A, Iwakura K, et al. Myocardial perfusion patterns related to thrombolysis in myocardial infarction perfusion grades after coronary angioplasty in patients with acute anterior wall myocardial infarction. Circulation 1996; 93: 1993-9. 